\title{
Launch of Articles in Press
}

Pediatric Research, together with our publisher, Lippincott Williams \& Wilkins, and with the assistance of HighWire Press, is very pleased to announce the launch of "Articles in Press." This new section of our website includes the full-text of all in-press articles, within two weeks of their acceptance.

Manuscripts in the Articles in Press section of the website have undergone full scientific review and a preliminary copyedit. After articles appear in Articles in Press, they are proofread and typeset. Then they are published in the definitive print and electronic issues of the journal, and are removed from the Articles in Press section of the website. However, they continue to remain in the archives of the site.

Articles in Press are citable and searchable in PubMed. The date a given article appears in this section of the website is the recognized publication date for the article. All Articles in Press are published with a Digital Object Identifier (DOI), a unique series of numbers and letters, by which the archived article can later be located.
It is our intention to continue to do all we can to speed the publication of important research. To that end we are also in the testing phase of implementing an electronic manuscript submission and review system.

We hope these initiatives will be as well received as the many new features introduced in Pediatric Research within the last few years. These include Research News, Commentaries, Review articles, and the online version of our journal, now accessed regularly by thousands of readers worldwide.

Adopting these exciting initiatives is in keeping with our goal of providing the best possible forum for the presentation of research findings in the study of childhood disease and development.

We hope you will soon take the time to visit Articles in Press. In order to do so, simply use the Articles in Press link on the Pediatric Research home page (www.pedresearch.org).

Alvin Zipursky Editor-in-Chief 